\title{
The Effects of Saikosaponin-d on Yeast Phagocytosis and Degradation in Peritoneal Macrophages: Related Increase in Fc Receptor Expression and Altered Cytoplasmic Organization
}

\author{
Yumiko Ushio and Hiroko Abe \\ The Research Institute of Oriental Medicine, Kinki University, Osaka 589, Japan \\ Received October 23, $1990 \quad$ Accepted March 19, 1991
}

\begin{abstract}
The effects of saikosaponin-d (ssd), isolated from Bupleurum radix, on phagocytic functions of mouse peritoneal macrophages were investigated in macrophage cultures after treatment in vivo. We also compared the ultrastructural appearances of macrophages from ssd-treated mice with those from control mice. The macrophages from ssd-treated mice showed a significant increase in phagocytosis, intraccllular killing of yeast and acid phosphatase activity. Treatment of mice with ssd also induced the $\mathrm{Fc}$ receptor expression in macrophages. The macrophages from ssd-treated mice showed more intense spreading on a glass surface than those from the control mice after a 60 min-incubation. Furthermore, the macrophages from ssdtreated mice seemed to possess a well-developed Golgi apparatus and the large vacuoles. The data suggest that the functional changes in the macrophages from ssdtreated mice are brought about by a modification in the surface membrane and the intracellular distribution.
\end{abstract}

The root of Bupleurum falcatum L., one of the chicf components of prescriptions used in traditional oriental medicine, is widely used in chronic hepatitis therapy (1) as well as in the treatments of renal and autoimmune diseases. Saikosaponins extracted from the roots of Bupleurum falcatum $\mathbf{L}$. as biological active components have an anti-inflammatory action $(2,3)$, an inhibitory effect on chronic hepatitis (4), an antinephritic effect (5) and immunopotentiating action. Furthermore, it has been demonstrated that saikosaponins modify the immune responses of $\mathrm{T}$ - and B-cells (6) and activate immunological functions of macrophages $(7,8)$. However, the effects of saikosaponin-d (ssd) on the phagocytic functions of mouse peritoneal macrophages are not yet well understood. We therefore tried a different approach to clarify the mechanism of ssd action on macrophages by administering ssd intramuscularly to mice. In the present study, we examined the in vivo effects of ssd on macrophages with regards to phagocytosis, intracellular killing of yeasts and acid phosphatase activity, since ssd, among all the saikosaponins, shows the strongest activities in most of the pharmacological actions. Furthermore, we investigated its effect on $\mathrm{Fc}$ receptor expression on the surface membrane of the macrophages obtained from mice treated with ssd, and we also examined the morphological changes in macrophages that correlated with the increase in the phagocytic activity of the cells. 


\section{MATERIALS AND METHODS}

\section{Preparation of ssd}

Ssd (Fig. 1) was isolated from the roots of Bupleurum falcatum L. by Dr. Ishii of Shionogi Research Laboratory (Shionogi and Co. Ltd., Osaka, Japan) using the methods of Kubota et al. (9) and Ishii et al. (10). The purity of this compound was assessed by thinlayer chromatography and ${ }^{13} \mathrm{C}-\mathrm{NMR}$ spectroscopy. Using this preparation, we examined the spreading and phagocytosis of macrophages after intramuscular administration of ssd to $\mathrm{C} 3 \mathrm{H} / \mathrm{HeJ}$ mice (LPS-nonresponder mice). The ssd-treatment of the $\mathrm{C} 3 \mathrm{H} / \mathrm{HeJ}$ mice induced a remarkable increase in macrophage spreading and phagocytic activity, showing that macrophage activation by ssd was not due to contamination by bacterial endotoxin.

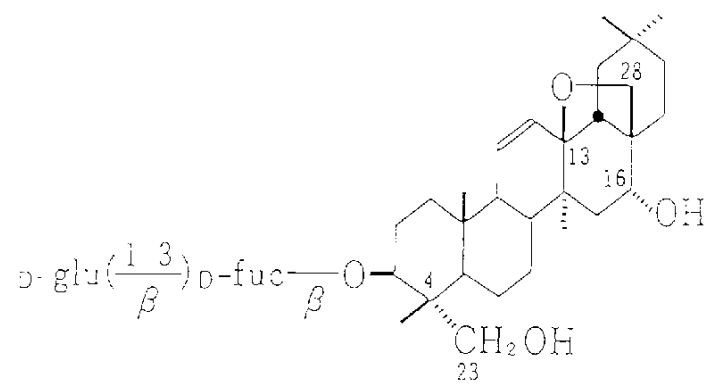

Fig. 1. The chemical structure of saikosaponin-d.

\section{Animals}

Male mice of the BALB/C strain, weighing from 25 to $30 \mathrm{~g}$ and obtained from the Shizuoka Experimental Animal Laboratory, were employed for all the experiments.

\section{Treatment with ssd}

Mice were injected intramuscularly with 1,5 or $10 \mathrm{mg} / \mathrm{kg}$ of ssd suspended in saline once a day for 3 days. Control mice were given saline. Macrophages were obtained $24 \mathrm{hr}$ after the last administration of ssd.

\section{Collection of peritoneal macrophages}

Mice were sacrificed by cxposure to ether.
The macrophages were collected by the method described by Lima and Kierszenbaum (11). The collected cells were incubated in Eagle's minimum essential medium (MEM) containing $10 \%$ heat-inactivated fetal calf serum (FCS) in culture dishes (Falcon, $10 \times$ $35 \mathrm{~mm}$ ) at $1 \times 10^{5}$ cells per dish for $2 \mathrm{hr}$ at $37^{\circ} \mathrm{C}$ in a $\mathrm{CO}_{2}$-incubator. After removing the non-adherent cells by washing with the medium, the macrophages were maintained in $10 \%$ FCS-MEM medium and used for the experiments. In some experiments, macrophages were plated in 12- or 24-well culture plates.

\section{Phagocytosis of yeast cells}

Living yeasts were pelleted by centrifugation, resuspended in 10\% FCS-MEM and added to the cultures at $1 \times 10^{6}$ per $\mathrm{ml}, 4 \mathrm{hr}$ after macrophages were plated on culture dishes. The cultures were incubated for $15 \mathrm{~min}$ at $37^{\circ} \mathrm{C}$ and fixed with $1 \%$ glutaraldehyde in phosphate-buffered saline (PBS) for $10 \mathrm{~min}$ at room temperature. The number of yeast cells ingested by macrophages was determined by phase contrast microscopy. Two hundred macrophages in random fields were determined, and the values were expressed as a mean \pm S.E.

\section{Intracellular killing of living yeasts}

We examined intracellular killing of living yeasts according to the method described by Grasso and Guay, Jr. (12). The macrophages obtained from control and ssd $(5 \mathrm{mg} / \mathrm{kg})$ treated mice were incubated with living yeasts for $15 \mathrm{~min}$ at $37^{\circ} \mathrm{C}, 4 \mathrm{hr}$ after the cells were plated on culture dishes. After the $15 \mathrm{~min}$ incubation, the extracellular yeasts were removed, the macrophages were gently washed with the medium, and one series of the cells obtained from control and ssd-treated mice were immediately exposed to distilled water for $30 \mathrm{~min}$ at room temperature. Liberated yeasts from the macrophages were diluted in PBS, plated on Sabouraud's dextrose agar plates, and then incubated at $30^{\circ} \mathrm{C}$ for $48 \mathrm{hr}$. Another series of the macrophages obtained from control and ssd-treated mice were incu- 
bated in fresh 5\% FCS-MEM medium without the extracellular yeasts for an additional 45 $\mathrm{min}, 105 \mathrm{~min}$ and $165 \mathrm{~min}$, lysed with distilled water, and the liberated yeasts were also plated on agar plates. The colonies were counted, and the total numbers of viable organisms per macrophage culture were calculated.

\section{Acid phosphatase activity}

Collected macrophages were incubated in 12-well culture plates for $4 \mathrm{hr}$, and then the supernatants were removed. The cells were washed with PBS and solubilized by incubating for $30 \mathrm{~min}$ with $0.1 \%$ Triton X-100. Acid phosphatase activity in the lysates was determined by a kit from Wako Pure Chemicals Co. Protein concentration of lysates was assessed by use of a dye reagent (Bio-Rad Laboratories.) (13).

\section{Fc receptor assay}

The presence of $\mathrm{Fc}$ receptors was detemined by using IgG-coated sheep red blood cells (SRBC). Washed SRBC were diluted to a $5 \%$ suspension in PBS. Two milliliters of this preparation was added to $50 \mu 1$ of a subagglutinating dilution of the IgG-anti-SRBC serum. Antibodies used were two anti-sheep erythrocyte monoclonal antibodies for subclasses IgG $2 \mathrm{a}$ and $\operatorname{IgG} 2 \mathrm{~b}$. This suspension was mixed and incubated for $30 \mathrm{~min}$ at $37^{\circ} \mathrm{C}$. After the incubation, the cells were washed three times with $\mathrm{PBS}$ and then resuspended in $5 \mathrm{ml}$ of veronal-buffered saline. To 24-well plates with monolayers of macrophages, $250 \mu 1$ of this preparation was added and incubated for 30 min at $37^{\circ} \mathrm{C}$ in $5 \% \quad \mathrm{CO}_{2}$. At the end of the incubation period, unattached sheep erythrocytes were removed by gently washing the wells three times with PBS. Then the cells were fixed with $2 \%$ glutaraldehyde for $10 \mathrm{~min}$ and stained with counterstain. In the assay of Fc receptor expression, the number of IgGcoated SRBC both attached and ingested by each macrophage was counted on at least 200 macrophages per well.

\section{Scanning electron microscopy}

Macrophages from the control and ssd (5 $\mathrm{mg} / \mathrm{kg}$ )-treated mice were plated on the glass surface, incubated in 5\% FCS-MEM medium at $37^{\circ} \mathrm{C}$ in $5 \% \mathrm{CO}_{2}$ for $1 \mathrm{hr}$ and fixed with $1 \%$ glutaraldehyde in PBS for $1 \mathrm{hr}$ at room temperature. The cells were then postfixed for $1 \mathrm{hr}$ with $1 \%$ osmium tetroxide in PBS, dehydrated in ethanol solutions of graded concentrations and dried in a critical point drying apparatus. The cells were covered with a layer of gold in an ion coater and examined by a Hitachi S-450 scanning electron microscope at an accelerating voltage of $15 \mathrm{kV}$. The cells were photographed with Kodak Tri-X film.

\section{Transmission electron microscopy}

Macrophages from the control and ssd (5 $\mathrm{mg} / \mathrm{kg}$ )-treated mice werc plated on culture dishes, incubated in 5\% FCS-MEM medium at $37^{\circ} \mathrm{C}$ in $5 \% \mathrm{CO}_{2}$ and $95 \% \mathrm{O}_{2}$ for $4 \mathrm{hr}$ and fixed for $1 \mathrm{hr}$ in $1 \%$ glutaraldehyde in PBS. The cells were postfixed for $1 \mathrm{hr}$ in $1 \%$ osmium tetroxide in PBS, stained in $3 \%$ uranyl acetate, dehydrated through a series of ethanol solutions of graded concentration, and embedded in Epon 812. The embedded block was removed from the culture dishes and trimmed, and ultra thin sections were made on an ultramicrotome, stained in uranyl acetate and lead citrate, and examined by a Hitachi HS-9 electron microscope.

\section{Statistical analysis}

All values represent the mean and standard error of at least five experiments. Statistical analysis was performed by Student's $\boldsymbol{t}$-test for unpaired observations.

\section{RESULTS}

Effects of ssd on the yeast phagocytosis and acid phosphatase activity of macrophages

The phagocytic and enzyme activities were examined $4 \mathrm{hr}$ after plating the macrophages obtained from the control and ssd-treated mice. The cells from mice treated with 5 and $10 \mathrm{mg} / \mathrm{kg}$ of ssd showed $70 \%$ and $52 \%$ in- 
creases in phagocytic activity, respectively, the effect of ssd being significant compared to the control cells. Moreover, the cells from mice treated with $10 \mathrm{mg} / \mathrm{kg}$ of ssd had a remarkably enhanced acid phophatase activity: a $40 \%$ increase compared to the control value (Table 1).

Effect of ssd on intracellular killing of yeasts in macrophages

The activity of macrophages in effecting intracellular killing of yeasts was determined $4 \mathrm{hr}$ after plating the macrophages obtained from mice treated with $5 \mathrm{mg} / \mathrm{kg}$ of ssd, the dose which showed the greatest increase of yeast phagocytosis (Fig. 2). Viable ycasts gra- dually declined with the time after plating of macrophages from both control and ssdtreated mice. The cells from ssd-treated mice elevated killing activity, $197 \%$ above that of the control, after incubation of the cells for an additional $45 \mathrm{~min}$. The yeast-killing activity of macrophages from ssd-treated mice was at the same level as that from control mice after incubation of the cells for an additional 165 $\min$.

\section{Effect of ssd on Fc receptor expression}

Fc receptor expression on the surface membrane of macrophages determined by the number of IgG-coated SRBC attached and in-

Table 1. Effect of ssd on phagocytosis of yeasts and acid phosphatase activity in macrophages

\begin{tabular}{lccc}
\hline Treatment $^{\mathrm{a})}$ & & $\begin{array}{c}\text { Phagocytosis } \\
\text { (cells/macrophage) }\end{array}$ & $\begin{array}{c}\text { Acid phosphatase } \\
\text { (mL/mg protein) }\end{array}$ \\
\hline Control & - & $2.3 \pm 0.2$ & $271.8 \pm 24.5$ \\
ssd & 1 & $3.2 \pm 0.5$ & $289.7 \pm 26.6$ \\
& 5 & $3.9 \pm 0.4^{\mathrm{c})}$ & $317.8 \pm 24.8$ \\
& 10 & $3.5 \pm 0.3^{\mathrm{c})}$ & $380.4 \pm 40.0^{\mathrm{b})}$ \\
\hline
\end{tabular}

The results were expressed as the mean \pm S.E. $(n=6)$. ${ }^{\text {a) }}$ Mice were given ssd intramuscularly once a day for 3 days. Peritoneal macrophages were harvested $24 \mathrm{hr}$ after the last administration. The phagocytosis of yeasts and acid phosphatase activity were determined $4 \mathrm{hr}$ after the cells were plated on culture dishes. ${ }^{\mathrm{b})} \mathrm{P}<0.05$, ${ }^{c)} \mathbf{P}<0.01$.

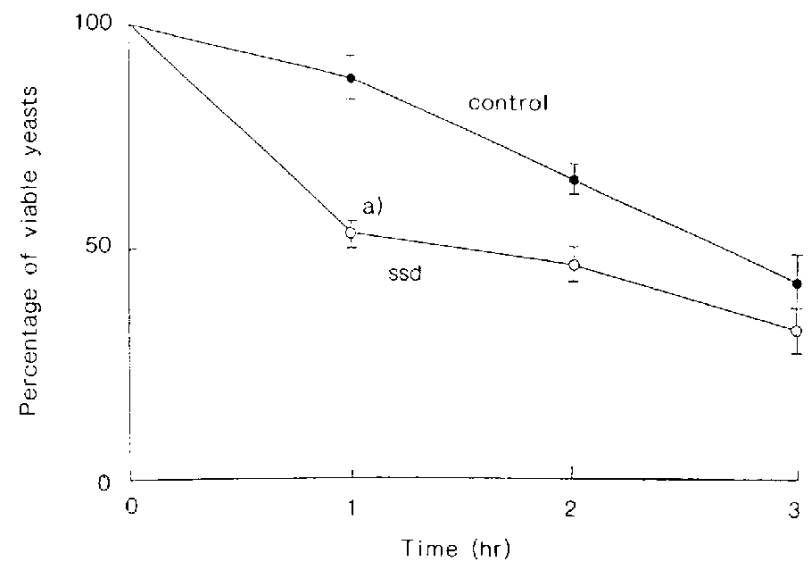

Fig. 2. Intracellular killing of ingested yeasts within cultured peritoneal macrophages. The killing activity of macrophages to yeasts was determined $4 \mathrm{hr}$ after plating macrophages obtained from the control $(\mathbf{O})$ and ssd $(5 \mathrm{mg} / \mathrm{kg})$-treated $(\bigcirc)$ mice. The values were expressed as the mean $上 \mathrm{~S}$.E. $(\mathrm{n}=5)$. ${ }^{\text {a) }} \mathrm{P}<0.05$. 
Table 2. Effect of ssd on Fc receptor expression on the surface membrane of macrophages

\begin{tabular}{lccc}
\hline Tretment $^{\text {(a) }}$ & & \multicolumn{2}{c}{ Fc receptor expression $^{\mathrm{b})}$} \\
\cline { 3 - 4 } & $(\mathrm{mg} / \mathrm{kg})$ & $\operatorname{IgGa}$ & $\operatorname{IgGb}$ \\
\hline \multirow{2}{*}{ Control } & - & $4.8 \pm 0.2$ & $4.5 \pm 0.2$ \\
ssd & 1 & $5.2 \pm 0.2$ & $5.2 \pm 0.2$ \\
& 5 & $5.6 \pm 0.2^{\mathrm{c})}$ & $5.8 \pm 0.2^{\mathrm{d})}$ \\
& 10 & $7.2 \pm 0.2^{(\mathrm{)})}$ & $6.4 \pm 0.3^{\mathrm{e}}$ \\
& 20 & $6.2 \pm 0.2^{\mathrm{d})}$ & $6.9 \pm 0.4^{\mathrm{e}}$ \\
\hline
\end{tabular}

The results were expressed as the mean number of IgG-coated SRBC attached and ingested by a single macrophage \pm S.E. $(n=5)$. ${ }^{a)}$ Mice were given ssd intramuscularly once a day for 3 days. Peritoneal macrophages were harvested 24 hr after the last administration. "Assay was carried out $4 \mathrm{hr}$ after the cells were plated on dishes. ${ }^{c} \mathrm{P}<0.05,{ }^{\mathrm{d}} \mathrm{P}<0.01,{ }^{e)} \mathrm{P}<0.001$.

gested by a single cell was remarkably increased after the mice were treated with 5,10 and $20 \mathrm{mg} / \mathrm{kg}$ of ssd, regardless of whether the IgG2a or IgG2b subclass was used (Table 2).

\section{Effect of ssd on macrophage surface structure}

Under scanning electron microscopy, the cells from control mice had a rounded shape and the degree of spreading $1 \mathrm{hr}$ over the glass surface was not marked (Fig. 3a). The macrophages from ssd $(5 \mathrm{mg} / \mathrm{kg})$-treated mice were well spread after $1 \mathrm{hr}$ of contact with the glass surface, and they showed enhanced phagocytic ability and intracellular killing activity towards living yeasts (Fig. 3b). The cells from ssdtreated mice displayed a large number of surface projections or microvilli and showed extensive morphological alterations.

Effect of ssd on ultrastructural features of macrophages

When examined by transmission electron microscopy, peritoneal macrophages obtained from control mice were usually found to be 8 to $14 \mu \mathrm{m}$ in diameter, as determined from representative mid-line sections (Fig. $4 \mathrm{a}$ ). The nucleus was eccentric in position and irregular in shape. The cell surface exhibited many membrane projections. The cytoplasm contained some dense granules corresponding to lysosmes. Though no quantitative analysis was carried out in the thin sections, the macro- phages from ssd $(5 \mathrm{mg} / \mathrm{kg})$-treated mice seemed to possess a more developed Golgi apparatus and larger vacuoles near the peripheral cytoplasm (Fig. 4b) as compared with those from control mice.

\section{DISCUSSION}

Activated macrophages differ from normal resting macrophages in morphology, spreading ability, organelle content, metabolism, lysosomal enzyme activity, phagocytic capacity and microbicidal activity (14). The macrophages from ssd-treated mice showed significantly increased activity in phagocytosis and intracellular killing of living yeasts. The phagocytosis of yeast, together with the ingestion of particles such as latex beads, has been classified as nonspecific phagocytosis distinct from receptor-mediated phagocytosis of particles coated with known ligands such as $\operatorname{IgG}$ or complement (15). Furthermore, the phagocytosis of yeasts has also been suggested to be mediated by a mannose receptor expressed on macrophages. We could not examine the mechanism of the phagocytosis of yeasts. Although the percent of yeasts killed intracellularly in the macrophages from ssdtreated mice was the same as that in those from control mice, the number of yeasts killed by the cells from ssd-treated mice seemed to be actually much larger than that by those 

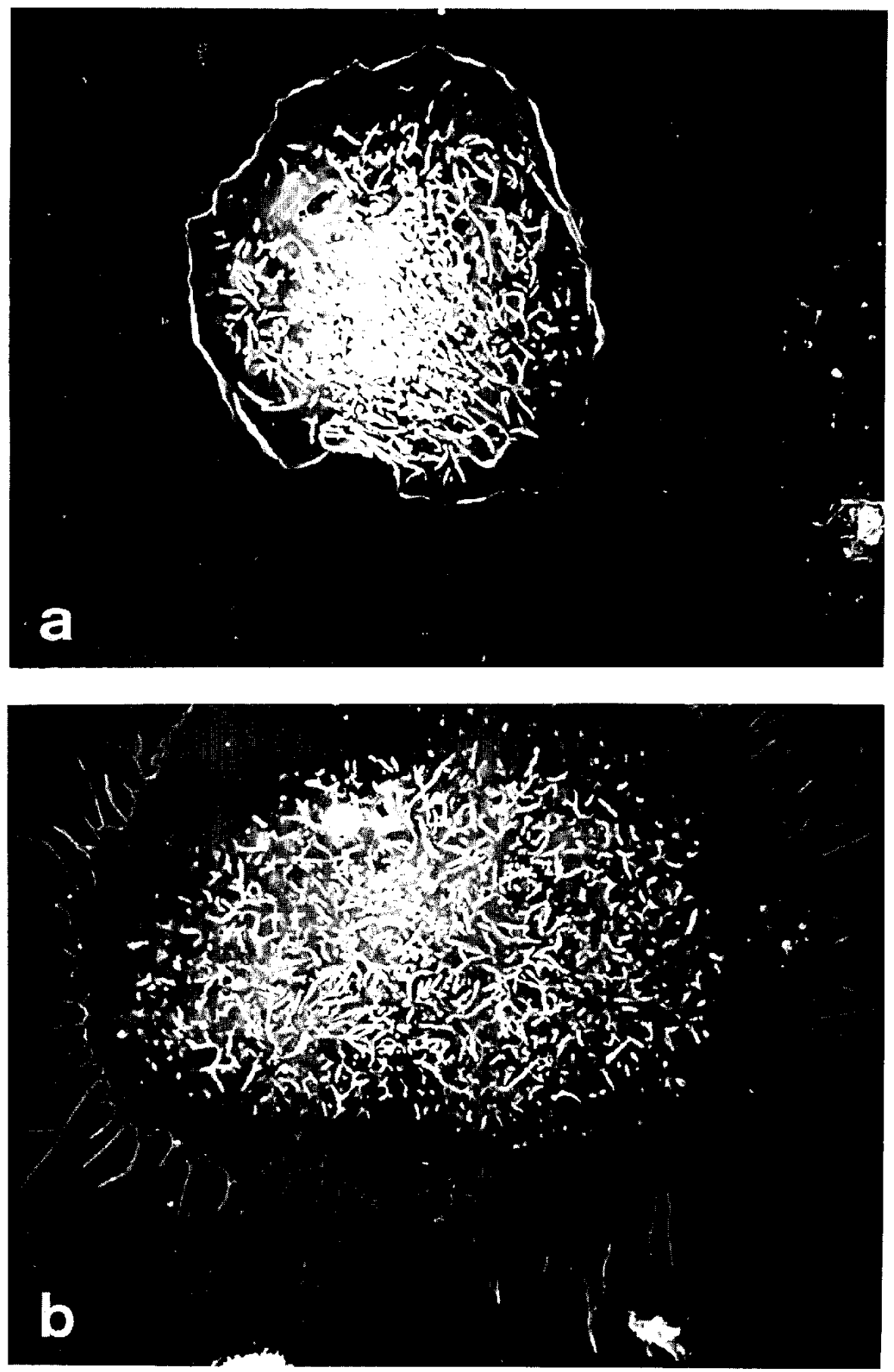

Fig. 3. Scanning electron micrographs of surface structures of peritoneal macrophages after $1 \mathrm{hr}$ of attachment to the glass surface. The cells from control mice had a rounded shape and showed slight spreading (a). The cells from ssd $(5 \mathrm{mg} / \mathrm{kg})$-treated mice were well spread, displaying a large number of surface projections or microvilli (b). $\times 800$. 


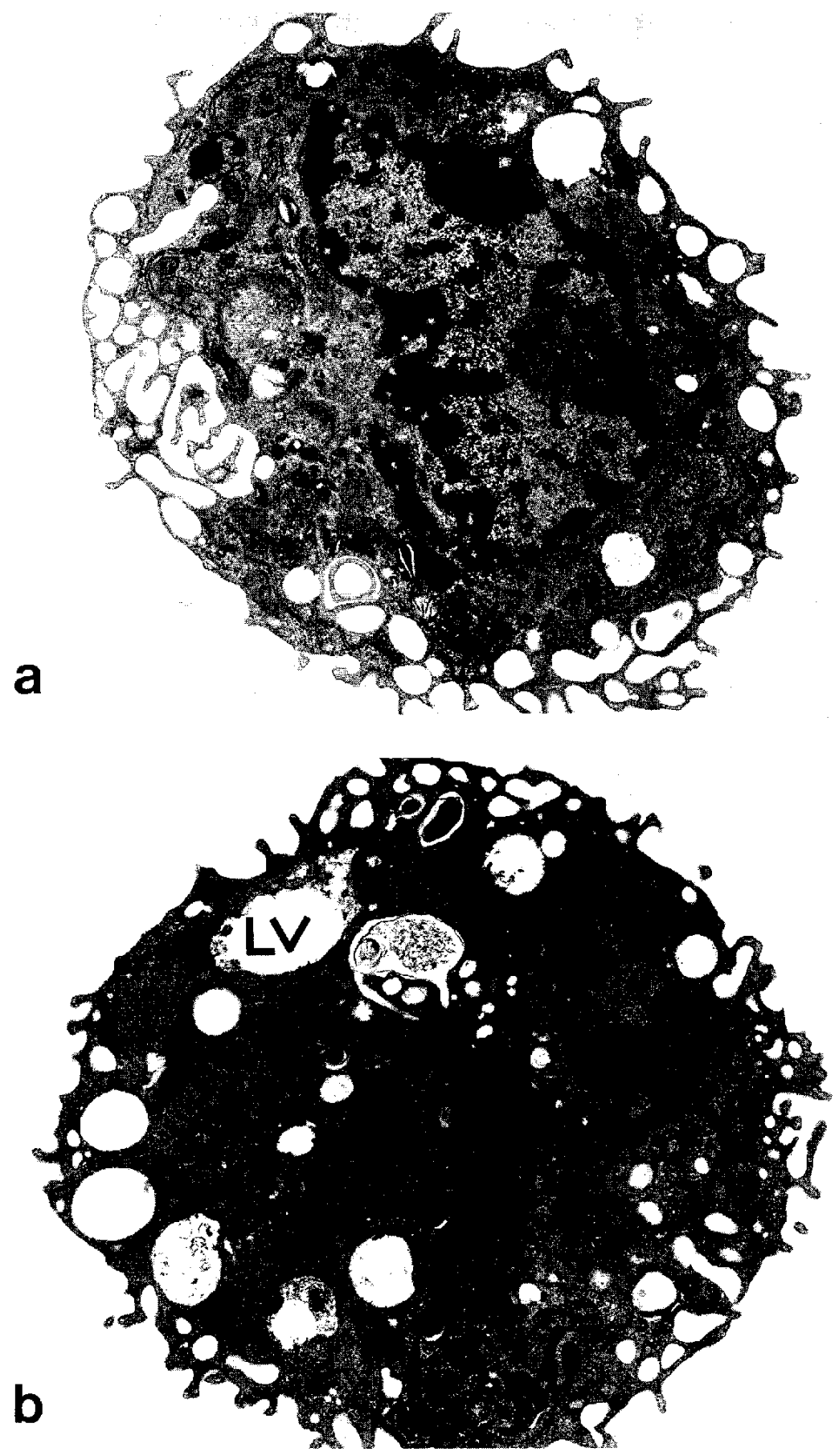

Fig. 4. Transmission electron micrographs of peritoneal macrophages $4 \mathrm{hr}$ after plating on culture dishes. a) Macrophage from a control mouse. b) Macrophage from an ssd $(5 \mathrm{mg} / \mathrm{kg})$-treated mouse. Large vacuole (LV) and well-developed Golgi apparatus (arrow). $\times 5,000$. 
from control mice because the macrophages from ssd-treated mice ingested many more yeasts than the control macrophages during the first $15 \mathrm{~min}$ incubation. Plasma membrane receptors for the Fc domain of IgG are expressed by a variety of mononuclear and lymphoid cell types (16). Fc receptors expressed on these cells play important roles in immunological processes, such as phagocytosis of opsonized particles, clearance of immune complexes, antibody-dependent cellular cytotoxicity $(\mathrm{ADCC})$, regulation of immune response and mediation of signals for the production of inflammatory mediators. Macrophages have two principal types of $\mathrm{Fc}$ receptors for IgG antibodies: IgG2a-specific FcR1 and IgG2bspecific FcR2 (17). We found that ssd increased the expression of both types of Fc receptors. This may lead to the cytotoxic effect.

We also found that macrophages from ssdtreated mice possessed increased acid phosphatase activity, compared to those from control mice. Acid phosphatase can serve as a marker of macrophage activation (18). It has been said that the levels of lysosomal enzymes are related to the capacity of macrophages to degrade biological materials (19).

It is obvious that macrophages do not present a unique and well-defined ultrastructure, but that the activation of their functions correlate with changes in some ultrastructural features (20). The macrophages from ssd-treated mice showed more intense spreading on the glass surface than those from control mice. The cell surface is of fundamental importance in endocytic processes since it contains membrane-associated components that specially recognize macromolecules $(21,22)$. The results of the present study suggest that both the increased spreading ability and the enhanced phagocytosis of living yeasts or IgG-coated SRBC are related to the modification of surface components induced by ssd treatment. In thin sections, the macrophages from ssdtreated mice seemed to be characteristically elongated and possessed a well developed Golgi apparatus and several large vacuoles. Lysosomal enzymes which are synthesized on the rough endoplasmic reticulum are transported to lysosomes through the Golgi complex via a receptor-mediated process (23). The alterations in the surface components and cytoplasmic organization of macrophages obtained from ssd-treated mice seemed to be related to the increased phagocytic activity, both non-specific and receptor-mediated, towards foreign particles.

Kumazawa et al. demonstrated that intraperitoneal injection of saikosaponins activated several functions of peritoneal macrophages (8). We also confirmed that peritoneal macrophages from mice treated intraperitoneally with ssd $(5 \mathrm{mg} / \mathrm{kg})$ showed significant increases in spreading and phagocytic activity. The minimum quantity of ssd necessary for macrophage activation was different in our experiments using the intramuscular route of administration $(150-300 \mu \mathrm{g} /$ mouse $)$ and those by Kumazawa et al. using the intraperitoneal route $(10 \mu \mathrm{g} /$ mouse). This may be because intraperitoneal injection of ssd induced direct stimulation of the peritoncal cavity, leading to macrophage activation, so that a smaller amount of ssd was effective on peritoneal macrophages in the case of intraperitoneal injection than intramuscular injection. The important finding in this study was not only the observed increase in non-specific phagocytic activity, but also the increase in $\mathrm{Fc}$ receptor expression accompanying the modification of surface components and intracellular organization in peritoneal macrophages, as induced by intramuscular administration of ssd.

In conclusion, considering the role of macrophages in immunological and nonimmunological processes that contribute to host resistance, the effects of ssd on the morphology and function of macrophages may produce an activation of resistance mechanisms in the host against infections. The immunological activation induced by ssd may significantly contribute to the anti-inflammatory effect, inhibition of chronic hepatitis and antinephritic effect that saikosaponins have already been reported to have. 


\section{REFERENCES}

1 Arichi, S.: Studies on chronic hepatitis. - From basic research to clinical application of SaikoProc. Symp. Wakan-Yaku 12, $107-113$ (1979) (Abs. in English)

2 Takagi, K. and Shibata, M.: Pharmacological studies on Bupleurum falcatum L. Anti-inflammatory and other pharmacological actions of crude saikosides. Yakugaku Zasshi 89, 1367-1378 (1969) (Abs. in English)

3 Yamamoto, M., Kumagai, A. and Yamamura, Y.: Structure and actions of saikosaponins isolated from Bupleurum falcatum L. I. Anti-inflammatory action of saikosaponins. Arzneimittelforschung 25 , 1021 - 1023 (1975)

4 Abe, H., Sakaguchi, M., Yamada, M., Arichi, S. and Odashima, S.: Pharmacological actions of saikosaponin isolated from Bupleurum falcatum L. Effects of saikosaponins on liver function. Planta Med. 40, 366-372 (1980)

5 Abe, H., Orita, M., Konishi, H., Arichi, S. and Odashima, S.: Effects of saikosaponin-d on aminonucleoside nephrosis in rats. Eur. J. Pharmacol. 120, 171 - 178 (1986)

6 Yamaguchi, N., Kohno, H., Tawara, M., Odashima, S. and Abe, H.: Effect of saikosaponin derivatives upon the immune response against $\mathrm{T}$ dependent and $T$-independent antigens in mice. Int. J. Immunopharmacol. 7, 827-832 (1985)

7 Ohuchi, K., Watanabe, M., Ozeki, T. and Tsurufuji, S.: Pharmacological influence of saikosaponins on prostaglandin $E_{2}$ production by peritoneal macrophages. Planta Med. 51, 208-212 (1985)

8 Kumazawa, Y., Takimoto, H., Nishimura, C., Kawakita, T. and Nomoto, K.: Activation of murine peritoneal macrophages by saikosaponin a, saikosaponin $d$ and saikogenin d. Int. J. Immunopharmacol. 11, 21-28 (1989)

9 Kubota, T., Tonami, F. and Hinoh, H.: The structures of saikosaponins A, B, C and D. Triterpenoid alcohols of Bupleurum falcatum L. Tetrahedron Lett. (1966, No. 7) $701-710$ (1966)

10 Ishii, H., Nakamura, M., Seo, S., Tori, K., Tozyo, T. and Yoshimura, Y.: Isolation, characterization and nuclear magnetic rcsonance spectra of new saponins from the roots of Bupleurum falcatum L. Chem. Pharmacol. Bull. (Tokyo) 28 ,
$2367-2383(1980)$

I1 Lima, M.F. and Kierszenbaum, F.: Lactoferrin effects on phagocytic cell function. 1. Increased uptake and killing of an intracellular parasite by murine macrophages and human monocytes. J. Immunol. 134, 4176-4183 (1985)

12 Grasso, R.J, and Guay, R.C., Jr.: A feasibility study to determine if microbicidal activity can be measured in dexamethasone-treated macrophage cultures. Adv. Exp. Med. Biol. 166, 279-283 (1983)

13 Bradford, M.: A rapid and sensitive method for the quantitation of microgram quantities of protein utilizing the principle of protein-dye binding. Anal. Biochem. 72. 248-254 (1976)

14 Kamovsky, M.L. and Lazdins, J.K.: Biological criteria for activated macrophages. J. Immunol, 121, $809-813$ (1978)

15 Silverstein, S.C., Steinman, R.M. and Cohn, Z.A.: Endocytosis. Annu. Rev. Biochem. 46, $669-722(1977)$

16 Unkeless, J.C., Fleit, H. and Mellman, I.S.: Structural aspects and heterogeneity of immunoglobulin Fc receptors. Adv. Immunol. 31, $247-270$ (1981)

17 Adams, D.O. and Hamilton, T.A.: The cell biology of macrophage activation. Annu. Rev. Immunol. 2, 283-318 (1984)

18 Cohn, Z.A.: The activation of mononuclear phagocytes: Fact, fancy and future. J. Immunol. 121, 813 - 816 (1978)

19 D'Arcy Hart, P.: Macrophage antimicrobial activity: Evidence for participation by lysosomes in the killing Saccharomyces cerevisiae by normal resident macrophages. Infect. Immun. 31, 828 - 830 (1981)

20 Ryter, A.: Relationship between ultrastructure and specific functions of macrophages. Comp. Immunol. Microbiol. Infect. Dis. 8, 119-133 (1985)

21 Ito, T., Ueda, M.J., Okada, T.S. and Ohnishi, S.: Phagocytosis by macrophages. The dissociation of the attachment and ingestion steps. J. Cell Sci. 51. $189-201$ (1981)

22 Zucherman, S.H. and Douglas, S.D.: Dynamics of macrophages plasma membrane. Annu. Rev. Microbiol. 37, 267-307 (1979)

23 Cohn, Z.A., Fedorko, M.E. and Hirsch, J.G.: The in vitro differentiation of mononuclear phagocytes. $\mathrm{V}$. The formation of macrophage lysosomes. J. Exp. Med. 123, $757-766$ (1969) 